\title{
Role of Neonatal Biomarkers of Exposure to Psychoactive Substances to Identify Maternal Socio-Demographic Determinants
}

\author{
Pilar Jarque ${ }^{1,2}$, Antonia Roca ${ }^{1,2}$, Isabel Gomila ${ }^{3,4}\left(\mathbb{D}\right.$, Emilia Marchei ${ }^{5}\left(\mathbb{D}\right.$, Roberta Tittarelli $^{6}$, \\ Miguel Ángel Elorza ${ }^{4,7}$, Pilar Sanchís 8,9 and Bernardino Barceló ${ }^{4,7, *(1)}$
}

1 Department of Pediatrics, Division of Neonatology, Son Espases University Hospital, Valldemossa Road, 79, 07120 Palma de Mallorca, Spain; pilar.jarque@ssib.es (P.J.); antonia.roca@ssib.es (A.R.)

2 Pediatric Multidisciplinary Research Group, Balearic Islands Health Research Institute (IdISBa), Valldemossa Road, 79, 07120 Palma de Mallorca, Spain

3 Clinical Analysis Service, Son Llàtzer University Hospital, Manacor Road, 07198 Palma de Mallorca, Spain; isabel.gomila@hsll.es

4 Clinical Toxicology Research Group, Balearic Islands Health Research Institute (IdISBa), Valldemossa Road, 79, 07120 Palma de Mallorca, Spain; miguelangel.elorza@ssib.es

5 National Centre on Addiction and Doping, Istituto Superiore di Sanità, Viale Regina Elena, 299, 00161 Rome, Italy; emilia.marchei@iss.it

check for updates

Citation: Jarque, P.; Roca, A.; Gomila, I.; Marchei, E.; Tittarelli, R.; Elorza, M.Á.; Sanchís, P.; Barceló, B. Role of Neonatal Biomarkers of Exposure to Psychoactive Substances to Identify Maternal

Socio-Demographic Determinants. Biology 2021, 10, 296.

https://doi.org/10.3390/

biology10040296

Academic Editors: Simona Zaami, Enrico Marinelli, Roberta Pacifici, Raffaele Giorgetti and Simona Pichini

Received: 5 March 2021

Accepted: 1 April 2021

Published: 4 April 2021

Publisher's Note: MDPI stays neutral with regard to jurisdictional claims in published maps and institutional affiliations.

Copyright: (c) 2021 by the authors. Licensee MDPI, Basel, Switzerland. This article is an open access article distributed under the terms and conditions of the Creative Commons Attribution (CC BY) license (https:// creativecommons.org/licenses/by/ $4.0 /)$.
6 Department of Anatomical, Unit of Forensic Toxicology, Histological, Forensic and Orthopedic Sciences, Sapienza University of Rome, Piazzale Aldo Moro, 5, 00185 Rome, Italy; roberta.tittarelli@uniroma1.it

7 Clinical Analysis Service, Clinical Toxicology Unit, Son Espases University Hospital, Valldemossa Road, 79, 07120 Palma de Mallorca, Spain

8 Department of Chemistry, University of the Balearic Islands, Valldemossa Road, km 7.5, 07122 Palma de Mallorca, Spain; pilar.sanchis@uib.es

9 Research Group in Vascular and Metabolic Pathologies, Balearic Islands Health Research Institute (IdISBa), Valldemossa Road, 79, 07120 Palma de Mallorca, Spain

* Correspondence: bernardino.barcelo@ssib.es; Tel.: +34-871205000 (ext. 65476)

Simple Summary: The rapid identification of newborns exposure to psychoactive drugs allows an appropriate clinical care. This study tried to identify maternal profiles that help to identify newborns exposed to psychoactive drugs during pregnancy. Mothers were interviewed using a questionnaire. The biomarkers of fetal exposure were measured in meconium samples. Statistical analysis was performed to identify the maternal characteristics that were most likely to be associated with drug use during pregnancy. Of a total of 372 mothers, $49(13.2 \%)$ tested positive for psychoactive drugs use: $24(49.0 \%)$ for cannabis, 11 (22.5\%) for ethyl glucuronide, six (12.2\%) for cocaine, and eight (16.3\%) for more than one psychoactive substance. The maternal characteristics that most likely identify substance use during pregnancy are: maternal age $<24$ years, lack of pregnancy care, single-mother families, and active tobacco smoking. The profiles of prenatal maternal exposure identified in a clinical setting can be used to request specific detection tests for identifying newborns exposed to these drugs.

Abstract: Background: The accurate assessment of fetal exposure to psychoactive substances provides the basis for appropriate clinical care of neonates. The objective of this study was to identify maternal socio-demographic profiles and risk factors for prenatal exposure to drugs of abuse by measuring biomarkers in neonatal matrices. Methods: A prospective, observational cohort study was completed. Biomarkers of fetal exposure were measured in meconium samples. The mothers were interviewed using a questionnaire. Univariate and multivariate logistic regression analyses were performed. Results: A total of 372 mothers were included, 49 (13.2\%) testing positive for psychoactive substances use: 24 (49.0\%) for cannabis, 11 (22.5\%) for ethyl glucuronide, six (12.2\%) for cocaine, and in eight (16.3\%) more than one psychoactive substance. Mothers who consumed any psychoactive substance (29.7 \pm 6.6 years) or cannabis (27.0 \pm 5.7 years) were younger than non-users (32.8 \pm 6.2 years, $p<0.05)$. Cocaine $(50.0 \%$ vs. $96.9 \%, p<0.05)$ and polydrug users $(37.5 \%$ vs. $96.9 \%, p<0.05)$ showed a lower levels of pregnancy care. Previous abortions were associated with the use of two or 
more psychoactive substances $(87.5 \%$ vs. $37.8 \%, p<0.05)$. Single-mother families $(14.3 \%$ vs. $2.5 \%$, $p<0.05)$ and mothers with primary level education $(75.5 \%$ vs. $55.1 \%, p<0.05)$ presented a higher consumption of psychoactive substances. Independent risk factors that are associated with prenatal exposure include: maternal age < 24 years (odds ratio: 2.56; 95\% CI: 1.12-5.87), lack of pregnancy care (odds ratio: 7.27; 95\%CI: 2.51-21.02), single-mother families (odds ratio: 4.98 ; 95\%CI: 1.37-8.13), and active tobacco smoking (odds ratio: 8.13 ; 95\%CI: 4.03-16.43). Conclusions: These results will allow us to develop several risk-based drug screening approaches to improve the early detection of exposed neonates.

Keywords: biomarkers; prenatal exposure; psychoactive substances; meconium; sociodemographic factors; neonatal intensive care unit

\section{Introduction}

Psychoactive substances use during pregnancy is an important issue that can have significant and persistent adverse consequences for pregnant women and their infants. The impact of this use is a public health concern, and it has important implications for healthcare providers. Understanding trends, patterns of use, and outcomes is critical to developing prevention campaigns, building awareness, and providing effective care [1].

Infants that are exposed to drugs of abuse during pregnancy have a greater risk of entering a Unit Neonatal intensive care and neonatal intermediate therapy [2,3]. The accurate assessment of fetal exposure through the objective measurement of biomarkers allows for the identification of maternal socio-demographic determinants and the results have cascade effects on treatments and social services [4]. Thus, neonatal toxicology testing is emerging as a crucial service that hospital laboratories provide to both patient care teams and social services. Moreover, the measurement in nonconventional neonatal matrices, such as meconium and hair, provides a long historical record of prenatal exposure to certain drugs and it can account for different periods of gestation: meconium for the second and third trimester of gestation, fetal hair for the third [5].

In the DSM-5 (Diagnostic and Statistical Manual of Mental Disorders, 5th Edition), the diagnostic term 'substance use disorders' (SUDs) has been introduced. This term combines psychoactive substance abuse and dependence into one category, with a continuum of severity [6]. SUDs during pregnancy have health, social, and legal consequences. The prevalence of psychoactive substance use in pregnancy is uncertain, but it is assumed that, during the first trimester, it is comparable to that of the general population. At the end stages of pregnancy, there are some patients who continue to consume psychoactive substances [2]. Cannabis use prevalence ranged from $8.1 \%$ at the beginning of pregnancy to $2.5 \%$ in the last trimester [7]. The results from the 2013 National Survey on Drug Use and Health showed that illicit drug consumption was lower among pregnant women during the third trimester than during the first and second trimesters ( $2.4 \%$ vs. 9.0 and $4.8 \%$ ). Similarly, alcohol use was lower during the second and third trimesters than during the first trimester (5.0 and $4.4 \%$ vs. $19.0 \%$ ) [8].

Prenatal exposure to drugs of abuse can negatively affect the pregnancy itself and the development, growth, and maturation of the fetus. The clinical manifestations of this exposure range from abortion, intrauterine death, malformations, low weight, prematurity, fetal distress, premature rupture of membranes, asphyxia, and cerebral infarction to abnormal heart and breathing patterns. This prenatal exposure is also associated with the neonatal withdrawal syndrome and physical and neurobehavioral disorders that become evident in early childhood [2,3]. On the other hand, newborns that are exposed to maternal ethanol during pregnancy can develop a spectrum of physical, cognitive, and behavioral disabilities, known as fetal alcohol spectrum disorders (FASD), whose most severe form, including morphological abnormalities, is defined as fetal alcohol syndrome (FAS) [9-11]. 
Toxicological studies performed in Spain and Italy have documented that fetal exposure to drugs of abuse (heroin, cocaine, and cannabis) was $7.9-15.9 \%$ and exposure to ethanol was $1.7-45 \%$ [12-16]. The prevalence of alcohol, cannabis, hypnotherapy, cocaine, ecstasy, and amphetamine use in Mallorca in 2015 was 79.7, 15.3, 9.9, 5.7, 2.2, and 1.2\%, respectively [17], but the prevalence of prenatal exposure to drugs of abuse in Mallorca is unknown. The island, with 896,038 inhabitants (2019 data from the Statistics Institute of the Balearic Islands), has $78 \%$ of the total population of the Balearic Islands. Mallorca is also a well-known international tourist destination.

National guidelines promote universal screening for substance use in pregnancy, but not universal testing [18]. Screening tests should be performed as a universally administered questionnaire designed to ascertain who is at high risk for having a substance use disorder in pregnancy [19]. Nevertheless, it is well known that maternal self-reports on psychoactive substance use history have proved to be unreliable [16].

In Spain, the Clinical Practice Guide for Care in Pregnancy and Puerperium suggests that pregnant women give up the consumption of psychoactive substances through cessation interventions. However, urine and alcohol drug screening is not given as a recommendation [20]. Similarly, The American College of Obstetricians and Gynecologists (ACOG) recommends routine screening for SUDs in all individuals, but screening is defined as questionnaires or patient interviews. The ACOG guideline states that the routine laboratory testing of biological specimens is not required [21].

There are several ethical, legal, and social considerations around toxicology tests in pregnancy that can be lost in the rush to test and confirm from a scientific and/or analytical perspective. The issue of consent is often raised in terms of drug screening, which in the specific case of pregnancy is complicated because drug use affects both the mother and neonate. Additionally, the ethical principal of "respect for persons" mandates that the woman give consent for the procedure given the social and legal ramifications of the test. Women also fear stigmatization and the legal consequences of drug use in pregnancy [22]. This leaves to individual institutions the decision to establish appropriate psychoactive substance testing policies.

The measurement of drugs and alcohol biomarkers in different neonatal matrices is an opportunity for clinical laboratories to assume a prominent role in the diagnostic management team for newborns and in the detection of SUDs in pregnant women [23]. Clinical laboratories can contribute to several distinct areas: the development of institutional and health system policies for psychoactive substances testing; education on the choice of specimen analysis; education that is related to specimen analysis; clinical interpretation of results; and, integration with maternal history and maternal toxicological results [24].

Despite the above considerations, the implementation of protocols for detecting prenatal psychoactive substances exposure through the analysis of biological biomarkers is scarce. Consequently, exposure cannot be detected during pregnancy, and it can only be diagnosed at birth if toxicological tests are performed. In the worst case, exposure will not be detected. This prevents early neonatal diagnosis and adequate medical treatment and social monitoring. Because newborns that are exposed to psychoactive substances during pregnancy have a higher risk of admission to the Neonatal Intensive and Intermediate Care Unit (NICU), this situation represents a challenge for their detection.

The measurement of biomarkers in neonatal matrices allows for the detection of this exposure. The accurate assessment of fetal exposure to psychoactive substances will provide correct information on the prevalence of drug abuse during pregnancy and consequent prenatal exposure to toxins in our NICU and will supply the basis for appropriate treatment and clinical and neurological follow-up of exposed newborns $[2,13,23,25]$.

Therefore, the objective of this study was to identify maternal sociodemographic profiles and risk factors for prenatal exposure to psychoactive substance by measuring of biomarkers in neonatal matrices. The results will allow for the development of risk-based biomarker screening approaches. These approaches will enable the early detection of exposed neonates admitted to the NICU and rapid intervention. 


\section{Materials and Methods}

\subsection{Study Subjects}

The work was a prospective observational study that was carried out in the NICU (Level IIIB) of the University Hospital Son Espases in Mallorca (Spain) between March 2018 and December 2019. Mother-infant dyads were recruited at the admission of neonates in the NICU. The following mother-infant dyads were excluded: mothers of neonates who presented with meconium aspiration syndrome, intrauterine intestinal perforation, delayed meconium evacuation, melaenic stools, severe asphyxia or death; and, mothers of neonates with no suspected prenatal exposure to psychoactive substances who were admitted on non-working days or during holidays periods or from whom meconium could not be collected.

\subsection{Neonatal Biomarkers Testing}

During the past decades, urine has been the specimen of choice for drugs of abuse screening. Neonatal urine are useful for determining acute exposure to drugs of abuse in the period immediately previous to delivery [23]. The two matrices of choice for neonatal research of biomarkers of exposure to alcohol in the last quarter or the last two trimesters of pregnancy are, respectively, the hair and meconium of the newborn.

Meconium is the first fecal matter passed by a neonate whose formation starts between the 12th and 16th week of gestation. Meconium analysis extends the window of detection of drug use to approximately the last 20 weeks of gestation, and it has been used to assess the prevalence of in utero drug exposure [23]. Neonatal hair starts growing during the last three to four months of pregnancy and therefore represents for exposure occurring in the last trimester [23].

Exposure was defined as the presence of psychoactive substances biomarkers in meconium samples that were collected within the first $24 \mathrm{~h}$ of life. The detection of drugs of abuse biomarkers was performed immediately and an aliquot was stored at $-20{ }^{\circ} \mathrm{C}$ for the subsequent detection of Ethylglucuronide (EtG).

Only in neonates with suspected prenatal exposure and when there was no meconium sample available to perform drug analysis in this matrix, analysis was performed on urine and/or neonatal hair. Drug testing was performed in urine and neonatal hair in 12 cases: in four cases meconium sample was not available and in eight cases meconium amount was insufficient to confirmatory tests. Urine bags were used to collect neonatal urine samples while, for neonatal hair analysis, a sample of 100-200 mg of hair was collected.

\subsubsection{Meconium Toxicology Testing for Analysis of Illicit Drugs}

Upon admission, meconium toxicology testing for analysis of illicit drugs biomarkers was performed using a combination of immunoassay and chromatography/mass spectrometry techniques. Meconium samples were homogenized and extracted, and the extracts were analyzed using an initial immunoassay (DRI ${ }^{\circledR}$ Assay, Abbott Laboratories Inc., North Chicago, IL, USA) for cocaine, opiates, cannabinoids (tetrahydrocannabinol: THC), amphetamines, ecstasy, and methadone, with cutoff concentrations of $20 \mathrm{ng} / \mathrm{g}$ for THC and $200 \mathrm{ng} / \mathrm{g}$ for the cocaine, opiate, amphetamine, ecstasy, and methadone metabolites [26,27]. Presumptive positive screens were confirmed using gas chromatography/mass spectrometry (GC/MS), with cutoffs at the limit of detection of the assays [27-29]: $50 \mathrm{ng} / \mathrm{g}$ for cocaine, opiate, amphetamine, ecstasy, and methadone metabolites; and, $5 \mathrm{ng} / \mathrm{g}$ for THC-COOH. The cocaine metabolites that were included in the GC/MS confirmation analysis were cocaine, benzoylecgonine (BE), and cocaethylene (CE); the opiate metabolites included morphine, codeine, and 6-monoacetylmorphine (6-MAM); the methadone metabolites included methadone and 2-ethylidene-1,5-dimethyl-3,3-diphenylpyrrolidine (EDDP); and, THC-COOH, amphetamine, methamphetamine, and 3,4-methylenedioxymethaphetamine (MDMA, known as ecstasy) were also confirmed by GC/MS. 


\subsubsection{Meconium Toxicology Testing for Analysis of EtG}

EtG was used as a biomarker for prenatal alcohol exposure. Meconium samples were analyzed using ultrahigh performance liquid chromatography coupled to tandem mass spectrometry (UPLC-MS/MS), with detection and quantification limits of $0.5 \mathrm{ng} / \mathrm{g}$ and $5 \mathrm{ng} / \mathrm{g}$, respectively [30]. The cutoff point to consider EtG positive was $30 \mathrm{ng} / \mathrm{g}$ [31].

\subsubsection{Urine and Hair Toxicology Testing for Analysis of Illicit Drugs}

Analysis of illicit drugs in urine were performed following the same protocol of meconium analysis [32-34]. The analysis of illicit drugs in hair was performed by GC-MS following previously published methods $[32,35,36]$.

\subsection{Data Collection}

Upon admission of neonate to the NICU and after the mother gave informed consent, a maternal interview was conducted to determine sociodemographic information and past and current psychoactive substances use. The questionnaire was structured, based on a written script and previous reports, and conducted by a pediatrician [12,13,37].

Thirteen questions were included on sociodemographic characteristics (age, nationality, family type, sexual orientation, and educational level), obstetric history, pregnancy control, and psychoactive substance use habits during pregnancy. Pregnancy care was considered adequate if serological tests (HIV, syphilis, and HBV), combined first trimester screening, O'Sullivan's test, and all three ultrasounds (first, second, and third trimesters) had been performed [20]. The substances investigated in this questionnaire included alcohol, cannabis, morphine, heroin, cocaine, amphetamines, ecstasy, methadone, alcohol, tobacco, and licit drugs used during pregnancy. Upon discharge, the cases that were referred to Social Services and the cases in which guardianship of the newborn was withdrawn were recorded.

The survey data and collected biological matrices (meconium, urine and hair) were coded in order to secure the participants' privacy, and the local Human Research Ethics Committee (Research Ethics Committee of the Balearic Islands CEI-IB, project number IB 3538/17 IP) approved the study protocol.

\subsection{Data Analyses}

The data obtained from neonatal biomarkers testing and the mother's interview were recorded in a Microsoft Office Excel 10 spreadsheet.

To obtain the demographic profile that is associated with prenatal exposure to psychoactive substances, the group with negative toxicological results for all of the tested substances was compared with the positive toxicological group for any psychoactive substance, the positive groups only for one psychoactive substance and the positive group for more than one psychoactive substance, respectively. In addition, the sociodemographic profiles associated with the consumption of cannabis, alcohol, or cocaine, were compared with each other to detect specific sociodemographic profiles that are associated with the use of cannabis, cocaine or alcohol. Values were expressed as the mean \pm standard deviation, median [interquartile range] or frequency (percentage).

Comparisons between "positive" and "negative" toxicology groups were performed by independent t-test or Mann Whitney $\mathrm{U}$ for quantitative variables; and, chi-square or Fisher's exact test for qualitative variables. Comparisons between "positive only for cannabis", "positive only for alcohol", "positive only for cocaine", "positive for more than one drug", and "negative toxicology" groups employed one-way ANOVA and LSD (Least Significant Difference) as a post-hoc test or Kruskal-Wallis test and Mann Whitney U test for continuous variables; and, chi-square for qualitative variables.

The Kappa coefficient was used to determine the agreement between the positive toxics detected in meconium and the consumption of positive toxics declared by the mother.

Univariate and multivariate binary logistic regression was used to identify the independent risk factors associated with prenatal exposure (positive toxicology), using as 
reference those cases with negative toxicology (odds ratio $=1$ ). Initially, the sociodemographic variables with $p<0.05$ were introduced into the model. The multivariate model was built step by step until the final model was obtained. The optimal cut-off values (those that optimize sensitivity and specificity) of the quantitative variables of the quantitative variables associated with psychoactive substance use were determined by receiver operating characteristic (ROC) curves and the maximum Youden (J) index, defined as sensitivity + specificity -1 . From the final model by binary logistic regression of the independent variables that are associated with psychoactive substance use, the probability for each case was calculated.

A two-tailed $p$-value less than 0.05 was considered to be statistically significant. Statistical analyses were performed using SPSS 27.0 (SPSS Inc., Chicago, IL, USA).

\section{Results}

During the 22-month recruitment period, 895 neonates were admitted to the NICU. Of these, 459 met the eligibility criteria and $372(81.0 \%)$ consented to participate in the study. Of the 372 women included in the study, $229(61.6 \%)$ were Spanish, with the mean ( \pm standard deviation, $S D$ ) age being $32.4 \pm 6.3$ years; 53 (14.2\%) had a higher university degree and $215(57.8 \%)$ had primary education. Table 1 shows the sociodemographic profiles associated with prenatal exposure to psychoactive substances.

Table 1. Sociodemographic profiles associated with prenatal exposure to psychoactive substances. Only variables with statistically significant differences between groups are shown.

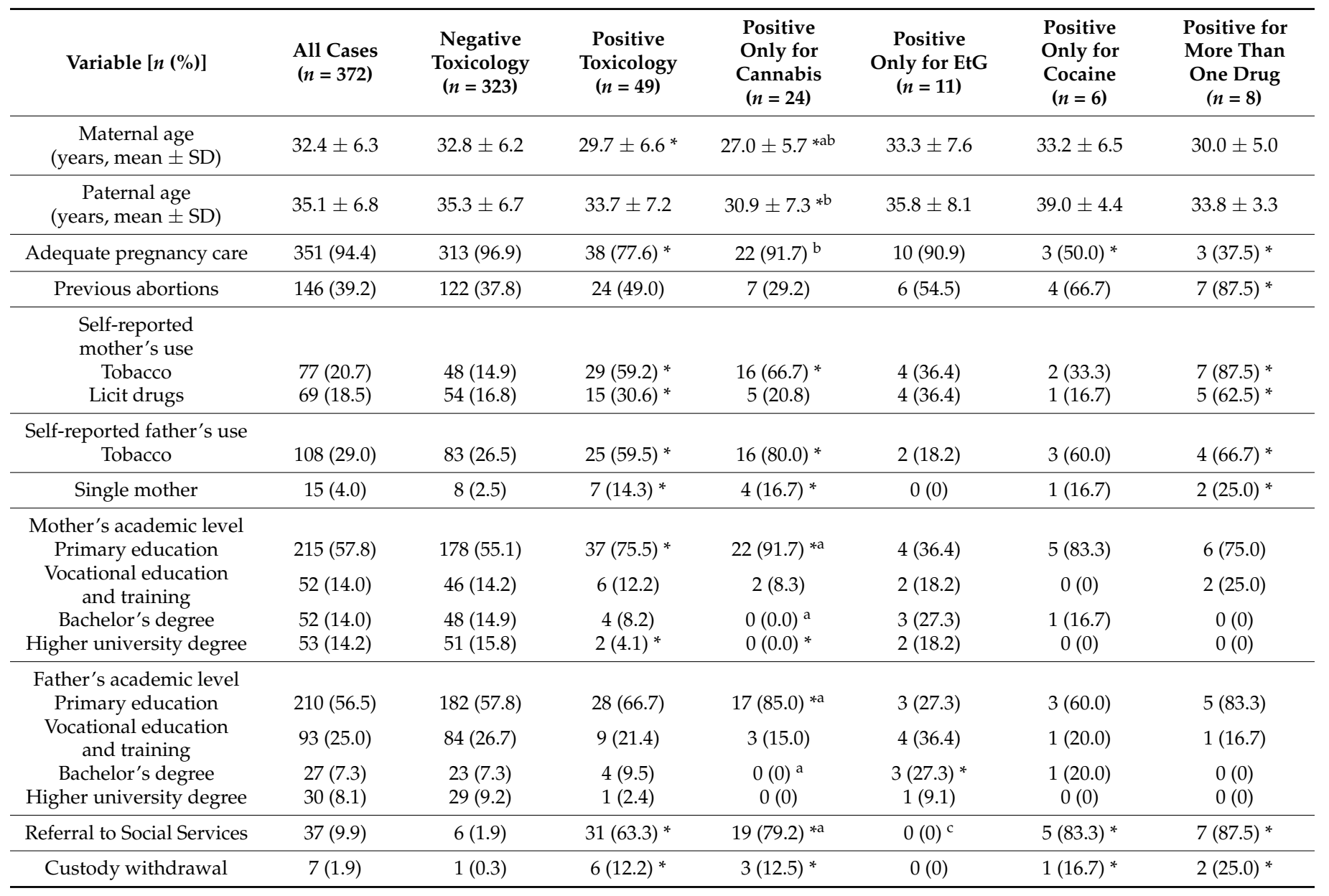

${ }^{*} p<0.05$ : statistically significant differences between negative and positive toxicology groups. ${ }^{a} p<0.05$ : statistically significant differences between cannabis and EtG groups. ${ }^{\mathrm{b}} p<0.05$ : statistically significant differences between cannabis and cocaine groups. ${ }^{\mathrm{c}} p<0.05$ : statistically significant differences between EtG and cocaine groups. EtG: ethyl glucuronide; SD: Standard deviation. 


\subsection{Neonatal Biomarkers Testing}

The biomarkers testing results were negative in $323(86.8 \%)$ cases and positive in $49(13.2 \%)$ cases. Among the positive cases, $24(49.0 \%)$ were for cannabis, $11(22.5 \%)$ for $\mathrm{EtG}$, six (12.2\%) for cocaine, and in eight (16.3\%) more than one psychoactive substance was detected.

The median concentration of EtG [quartile1-quartile3] in the meconium samples considered positive was: 71.1 [45.0-113.5] ng/g. 28 (7.5\%) cases had EtG concentrations between 5 and $30 \mathrm{ng} / \mathrm{g}$, with a median [interquartile range] of: 12.4 [9.4-18.1] ng/g.

Hair samples were positive for cocaine in eight cases, for cannabis in two cases and for cocaine and cannabis in one case. In eight cases, cocaine was confirmed in urine. One case was negative in both samples. EtG was detected in meconium samples in all cases. This means that consumption occurred during the second and third trimester of pregnancy.

When the positive toxicology results were compared with data recorded in the questionnaire, the agreement obtained for each substance were: $66.7 \%(k=0.671 ; p<0.001)$ for cannabis, $45.5 \%(k=0.564 ; p<0.001)$ for EtG, $16.7 \%(k=0.260 ; p=0.007)$ for cocaine, and $25.0 \%(k=0.358 ; p=0.001)$ for more than one psychoactive substance use.

\subsection{Sociodemographic Profiles Associated with Prenatal Exposure to Psychoactive Substances}

Table 1 reports the parental socioeconomic and demographic characteristics in relation to the toxicology results obtained by meconium biomarkers analysis. Only variables with statistically significant differences between groups are shown. The patterns were obtained by comparing the toxicology results with the sociodemographic data of the questionnaire.

\subsubsection{Age}

Psychoactive substance use was associated with a significantly younger age of mothers when compared to non-users ( $29.7 \pm 6.6$ vs. $32.8 \pm 6.2$ years, $p<0.05)$. Cannabis use was associated with both younger mothers $(27.0 \pm 5.7$ vs. $32.8 \pm 6.2$ years, $p<0.05)$ and younger fathers ( $30.9 \pm 7.3$ vs. $35.3 \pm 6.7$ years, $p<0.05)$. Moreover, the cannabis users were younger than the alcohol users $(27.0 \pm 5.7$ vs. $33.3 \pm 7.6$ years, $p<0.05)$ and the cocaine users $(27.0 \pm 5.7$ vs. $33.2 \pm 6.5$ years, $p<0.05)$.

\subsubsection{Lack of Adequate Pregnancy Care}

A lack of adequate pregnancy care was associated with substance use (77.6\% vs. $96.9 \%$, $p<0.05)$, specifically with cocaine $(50.0 \%$ vs. $96.9 \%, p<0.05)$ and more than one psychoactive substance ( $37.5 \%$ vs. $96.9 \%, p<0.05)$. Cocaine users also showed lower levels of care than cannabis users $(50.0 \%$ vs. $91.7 \%, p<0.05)$.

\subsubsection{Previous Abortions}

Exposure to more than one psychoactive substance during pregnancy was associated with a significantly higher percentage of previous abortions ( $87.5 \%$ vs. $37.8 \%, p<0.05$ ).

\subsubsection{Single Mother}

Single mothers used psychoactive substances $(14.3 \%$ vs. $2.5 \%, p<0.05)$, specifically cannabis $(16.7 \%$ vs. $2.5 \%, p<0.05)$ and more than one psychoactive substance $(25.0 \%$ vs. $2.5 \%, p<0.05)$, more frequently than mothers with a partner.

\subsubsection{Academic Level}

A lower education level of mothers was associated with substance use during pregnancy. More frequently, psychoactive substance-using mothers had only completed primary level education $(75.5 \%$ vs. $55.1 \%, p<0.05)$. In those with a university degree, psychoactive substance use was much lower $(4.1 \%$ vs. $15.8 \%, p<0.05)$.

The academic profiles were different between cannabis and alcohol consumers. Education only to primary level was more frequent in cannabis users than in alcohol users, both in mothers $(91.7 \%$ vs. $36.4 \%, p<0.05)$ and fathers $(85.0 \%$ vs. $27.3 \%, p<0.05)$. In contrast, 
holding a bachelor's degree is less common in mothers and fathers who used cannabis as compared to those who consume alcohol ( $0 \%$ vs. $27.3 \%, p<0.05$ in both).

\subsubsection{Self-Reported Tobacco Smoking and Licit Drug Use}

Self-reported tobacco smoking $(59.2 \%$ vs. $14.9 \%, p<0.05)$ and licit drug use $(30.6 \%$ vs. $16.8 \%, p<0.05)$ was significantly associated with psychoactive substance use. In addition, positive cases were significantly associated with tobacco consumption by the father $(59.5 \%$ vs. $26.5 \%, p<0.05)$.

\subsubsection{Referral to Social Services and Custody withdrawal}

The reporting of cases to Social Services $(63.3 \%$ vs. $1.9 \%, p<0.05)$ and withdrawal of guardianship of the neonate $(12.2 \%$ vs. $0.3 \%, p<0.05)$ were more frequent in cases in which psychoactive substance use was detected. The notification to Social Services was frequent in cases of cannabis use $(79.2 \%$ vs. $1.9 \%, p<0.05)$ and cocaine use $(83.3 \%$ vs. $1.9 \%$, $p<0.05)$. There were no cases reported to Social Services relating to alcohol use.

\subsection{Independent Sociodemographic Risk Factors Associated with Prenatal Exposure}

The final model showed that the independent sociodemographic risk factors that were associated with prenatal exposure were: maternal age $<24$ years (odds ratio: 2.56 ; $95 \% \mathrm{CI}$ : 1.12-5.87), lack of pregnancy care (odds ratio: 7.27; 95\%CI: 2.51-21.02), single mother (odds ratio: 4.98 ; $95 \%$ CI: $1.37-18.13$ ), and mother with active tobacco smoking (odds ratio: 8.13 ; 95\%CI: 4.03-16.43) (Figure 1).

A

Maternal age $<24$ years

Lack of pregnancy care

Single mother

Mother active tobacco smoking
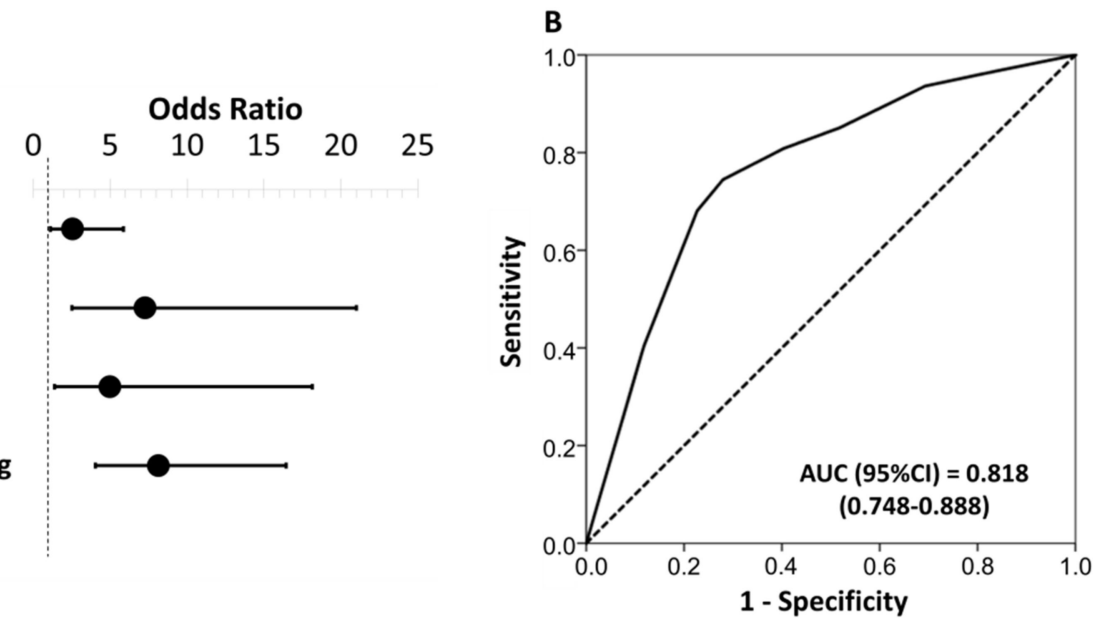

\begin{tabular}{|c|c|c|c|c|c|c|}
\hline & Crude O.R. & $(95 \% \mathrm{Cl})$ & $P$-value & Ajusted O.R. & $(95 \% \mathrm{Cl})$ & $P$-value \\
\hline Maternal age $<24$ years & 3.64 & $(1.77-7.47)$ & $<0.001$ & 2.56 & $(1.12-5.87)$ & 0.027 \\
\hline Lack of pregnancy care & 8.38 & $(2.88-24.37)$ & $<0.001$ & 7.27 & $(2.51-21.02)$ & $<0.001$ \\
\hline Single mother & 6.56 & $(2.26-19.02)$ & 0.001 & 4.98 & $(1.37-18.13)$ & 0.015 \\
\hline Mother active tobacco smoking & 8.31 & $(4.35-15.86)$ & $<0.001$ & 8.13 & $(4.03-16.43)$ & $<0.001$ \\
\hline Licit drugs mother use & 2.19 & $(1.12-4.30)$ & 0.023 & & & \\
\hline Mother's Primary Education level & 2.51 & $(1.26-4.99)$ & 0.009 & & & \\
\hline Mother's Higher University degree & 0.23 & $(0.05-0.96)$ & 0.044 & & & \\
\hline
\end{tabular}

Figure 1. Binary logistic regression of the sociodemographic risk variables associated with prenatal psychoactive substance exposure. Forest plot (A) and receiver operating characteristic (ROC) curve (B) of the multivariate model obtained. Note: The table indicates the crude and adjusted odds ratios (O.R.) with their confidence intervals in parentheses. The optimal cutoff values were determined by the maximum Youden $(\mathrm{J})$ index, defined as sensitivity + specificity -1 . A comparison of the expected and observed frequencies was made by the Hosmer-Lemeshow goodness-of-fit test $(p=0.551)$ and by its ROC curve and its area under the curve (AUC) indicating a good fit for the model. 


\section{Discussion}

In this study, sociodemographic profiles and independent risk factors that were associated with prenatal exposure to psychoactive substance were identified by the measuring of biomarkers in neonatal matrices. To our knowledge, this is the first study of these characteristics carried out in our country in a NICU.

The prevalence estimates for prenatal substance use vary widely and they have been difficult to establish. The true prevalence of drug use among pregnant women is difficult to ascertain and widely vary across countries $[38,39]$. Therefore, clinical laboratories through the measurement of biomarkers of exposure to psychoactive substances in biological matrices can play an essential role in assessing the real fetal exposure, allowing for the generation of appropriate policies and interventions.

The top three substances detected, cannabis, EtG, and cocaine, showed a similar pattern to the drug abuse results that were published to Spain by the European Monitoring Centre for Drugs and Drug Addiction in women between aged 15 and 35 years, lending high reliability to the data [40]. As expected, cannabis was the most frequently detected substance. The incidence of prenatal cannabis use detected in this study $(8.3 \%$, including cases positives for more than one drug), was in the range of other studies performed using drug testing in meconium samples (2.8 to $10.3 \%$ ) [21,41,42].

After cannabis, the second detected substance was EtG (4.3\% of samples over established cut-off, including cases positives for more than one drug). Moreover, EtG was also detectable, although at levels that were below the established cutoff, in an additional $7.5 \%$ of patients. In agreement with previously reported data, our results show the high prevalence of women consuming a non-negligible amount of alcohol during their pregnancies [43].

The third detected substance was cocaine (3.2\%, including cases positives for more than one drug). The obtained results were similar to the results reported in meconium samples in other studies, ranging from 1.2 to $5.6[13,44,45]$.

Finally, in our study one sample was found positive to opiates and one positive to methadone in one mother in opioid substitution treatment. Ecstasy or amphetamines were not detected. These findings were lower than the results found in other cohorts of Mediterranean area $[12,37,46]$.

The EtG levels found in the positive meconium samples were in the range of previous studies, with concentrations between 71-208 $\mathrm{ng} / \mathrm{mg}$ [31,47,48]. Meconium samples were considered to be positive for cannabis and cocaine when they were above the detection limit of the assays ( $5 \mathrm{ng} / \mathrm{g}$ for THC-COOH and $50 \mathrm{ng} / \mathrm{g}$ for cocaine metabolites), but the levels were not quantified.

When considering the positive cases detected in our study (13.2\%) and the annual average of live neonates (8053 infants in the last five years according to data from the Statistics Institute of the Balearic Islands), more than 1000 mothers and babies in Mallorca could test positive every year. However, this number is likely to be higher than the real one, since neonates that are exposed to psychoactive substances are more likely to be admitted to a NICU than those non-exposed. Nevertheless, this does help demonstrate the potential magnitude of this issue in the study area.

Drug use during pregnancy is a risk factor for both maternal and fetal complications. Additionally, children that are exposed to drug use are susceptible to many adverse longterm effects $[2-4,10,49,50]$. Some studies have associated cannabis use during pregnancy with lower birth weights and an increased incidence of tremors, exaggerated startles, and diminished crying in the neonate and longer gestations. In addition, children exposed to cannabis had a lower performance on standardized tests, indicating that long-term behavioral and neurodevelopmental issues may occur in these children $[1,50]$.

With cannabis being touted on the Internet as a safe treatment of nausea during pregnancy, current rates of use of cannabis during pregnancy are a concern. However, there are currently no indications for its use during pregnancy and research is needed before cannabis can be considered for use in hyperemesis gravidarum. Koren et al. suggested that cannabis should be tested in appropriately powered control trials for this severe and 
protracted maternal condition, addressing both maternal effect and potential adverse fetal effects [51,52]. Pregnant women who are using cannabis in pregnancy should be counseled about the lack of safety data and the possible adverse effects of THC on the developing fetus and referred to their health care provider for alternative treatments that have better pregnancy-specific safety data $[40,50]$.

Alcohol exposure during pregnancy can have many serious consequences for the offspring, including miscarriage, stillbirth, preterm birth, intrauterine growth retardation, teratogenicity, and alcohol-related neurodevelopmental disorders. The fetal alcohol spectrum disorder (FASD) describes the consequences that are associated with prenatal alcohol exposure. The clinical presentation of the disease is inconsistent, some lacking evidence of central nervous system neurodevelopment abnormalities. Typically, for the definite diagnosis of FASD, the confirmation of prenatal ethanol exposure is needed, because some of the characteristics of the disease, in particular, physical, may be absent [22,53,54].

Prenatal cocaine exposure is associated with low birth weight, prematurity, spontaneous abortions, stillbirths, and microcephaly. In addition, maternal hypertension, tachycardia, vasoconstriction, increased uterine contractility, and placenta complications have been described, including placental abruption, and an increased risk of diminished blood flow to the fetus. Exposure to cocaine during childhood can increase the risk for hypertension, ventricular arrhythmia, seizures, and intracranial bleeding. Behavioral problems also present themselves during development to both prenatally and postnatally exposed children. Infants that are exposed in utero are found to have attention deficits with an increased incidence of attention-deficit/hyperactivity disorder and transient central and autonomic nervous system signs and symptoms. Prenatal cocaine exposure is associated to sudden infant death syndrome [54-57].

Poly-substance use is common among substance users, and this and the acuteness or the chronicity of the use may also modify or exacerbate the individual effects on maternal and fetal health [1]. In our study, poly-substance use was associated significantly with previous abortions; these findings were in accordance with other studies [12,13,37,41,46,58]. As in other studies, SUDs were not associated with a higher frequency of preterm births [12-14,37,46].

Moreover, pregnant women who are substance users often have complex social and mental health issues and these women need access to assertive outreach care from specialists in addiction and mental health. There is also the additional risk of transmission of viral infections (hepatitis B, hepatitis C, or HIV).

Taken together, these adverse consequences of substance use to the developing fetus and mother are complex, and efforts should be made to identify and support women who are using substances. It is important that health care providers understand the risk factors and adverse consequences of substance use during pregnancy on maternal and fetal health to provide appropriate advice to substance-using pregnant women [1].

Th obtained data underline the usefulness of meconium testing as an analytical tool for a more accurate identification of neonates exposed in utero to drugs of abuse compared to the identification based only on maternal questionnaire. The toxicological results objectively demonstrated that sociodemographic characteristics, such as maternal age, lack of pregnancy care, being a single mother, or smoking increased the risk of prenatal exposure to toxic substances in the neonate. Our findings are in agreement with the well-known under-reporting of alcohol and drug use by pregnant women [59].

The average age of mothers that were included in our study (32.4 years) was similar to that previously reported in the international literature $[37,42,58,60]$. Psychoactive substance use was significantly associated with younger age, as reported in other studies [42] Pregnant cannabis users, as well as her partners, were significantly younger than non-users and cocaine and alcohol users. The pregnant cannabis users were younger than those that were reported in other studies (28.9-30.1 years) $[5,13,37]$, but pregnant cocaine and alcohol users were older $[12,13,46,48]$. The results showed that mothers under 24 were over three and a half times more likely to use psychoactive substances during pregnancy. Thus, there 
is a need to target initiatives to prevent prenatal drug exposure, especially cannabis, at younger age groups.

Many studies have documented that substance-using women, particularly cocaine or opiate users, are significantly less likely to obtain pregnancy care, despite accruing greater benefit from it $[14,40,52,61,62]$. Our regression results showed that mothers with a lack of pregnancy care was over eight times more likely to use psychoactive substances. Moreover, this lack of pregnancy care was significantly associated with the use of cocaine or of more than one psychoactive substance. The low rate of pregnancy care in cocaine and poly-drug users could be explained by: (1) surrounding circumstances and chaotic lifestyles, (2) resource or attitudinal barriers to care, such as fear of police report, or (3) some direct, disruptive effect of the particular substance $[2,61]$.

In contrast, the lack of pregnancy care was not associated with cannabis or alcohol use. Schempf el al. also found cannabis to be not independently related to pregnancy care [61].

The adequate pregnancy care that is associated with alcohol use could be explained by the underestimation of alcohol consumption by the mothers themselves [48], which implies adequate pregnancy care, despite continuing with substance use.

Co-use of tobacco and illicit drugs, particularly cannabis, is relatively high during pregnancy, as reported previously $[47,52]$. The results indicate that women who smoke cigarettes are more than six and a half times more likely use psychoactive substances during pregnancy. Given the strong association between smoking and other drug use, clinicians should routinely assess for illicit drug use in women who smoke during pregnancy [63]. Smoking tobacco has a significant relationship with cannabis use during pregnancy, but not with cocaine use, as also reported in other studies $[5,13,37,42,46]$. As in our work, tobacco consumption was declared by the mother and no toxicological analyses were performed.

Our results showed a significantly relation between licit drugs and illicit drug use in pregnant women. Published data on this association are scarce, but prescription drug abuse, especially opiates, benzodiazepines, and stimulants prescribed for attentiondeficit/hyperactivity disorder, often co-occurs with other illicit substances or alcohol abuse [61]. Joya et al. [46] founded a correlation between cocaine and antidepressant use. The association between licit and illicit drug represents an increased risk to the mother and the fetus.

Even exposure to drugs of abuse have been associated with lack of education, some studies found no associations with academic level [37,46]. Our data showed that only having a primary level education was more common in cannabis users, both in mothers and fathers alike, in agreement with other studies [64,65]. The association between alcohol consumption and a higher academic level has been described previously [60]. In our study, an association was found between fathers with a bachelor's degree and a higher frequency of alcohol consumption, although no differences were found in mothers. No clear association was found between academic level and cocaine use.

In a previous study that was performed in Spain, of the mothers who tested positive for psychoactive substance use, $40-60 \%$ had custody of their child removed [66]. In our population, child removed frequencies were lower, with a maximum of $25 \%$ in cases of polydrug use.

The referral to Social Services of cases of cannabis, cocaine and other psychoactive substance use was very frequent. However, the results of alcohol exposure were not available in the perinatal period and detected cases of alcohol consumption could not be referred to Social Services. These data suggest that social services may need to be involved with a larger proportion of mothers as, there may be mothers with addiction issues needing support, especially related to non-detected alcohol consumption.

Our results confirmed previous data in the literature, with psychoactive substance use during pregnancy being independently associated with low maternal age, a lack of pregnancy care, single mother status, and smoking habits [13,66-69]. These factors can lead to suspicion of a SUD, and can be used for the purpose of preventive health and policy 
strategies, especially in cases when the mother's lack of awareness regarding health care, pregnancy planning, and low economic resources are also evident.

In our study, the potential SUDs in mothers were identified by the neonatologists. This was done due to the lack of attention to pregnancy and detection of psychoactive substance use, which meant that SUDs were not detected during pregnancy. Therefore, these studies reinforce the need to strengthen strategies for identifying such women.

Other risk factors that must be assessed in the preventive health and policy strategies are a history of mental illness [4] and domestic violence, as well as the presence of infectious diseases and employment status of the mother. These factors were outside the scope of the current study.

The limitations of this study first include that biomarkers of tobacco, new synthetic psychoactive drugs, or licit drug use were not analyzed. Mothers are often reluctant to admit having used drugs or they may not even be aware that they had been using a medication, so the measurement of drug concentrations (licit or illicit drugs) provides useful information for immediate infant treatment and subsequent medical follow-up.

Secondly, the results of alcohol exposure were not available in the perinatal period, which made it impossible to use them in early clinical or social health management. Finally, biomarkers analysis in meconium samples only detects psychoactive substance use in the second and third trimesters of pregnancy.

\section{Conclusions}

In summary, the risk factors that were identified in a clinical setting can be used to improve the detection of prenatal exposure to psychoactive substances. Our study demonstrates the usefulness of these factors in a real scenario: how the NICU and clinical toxicology laboratory work in real time for the early detection of exposed neonates.

Furthermore, the study showed that cannabis is the most frequently detected psychoactive substance in neonates admitted to our NICU, followed by alcohol and cocaine, reinforcing the need of suitable biomarkers for their detection. These results will allow us to develop several risk-based drug screening approaches to improve the early detection of exposed neonates admitted to the NICU and provide rapid intervention. The laboratory results have cascading impacts on effective medical care and treatment if this service works in real time.

The prevalence estimates for prenatal substance use vary widely and have been difficult to establish. Therefore, the work of clinical laboratory, as presented in this study, through the measurement of biomarkers of exposure in biological matrices play an essential role in assessing the real fetal exposure, allowing for the generation of appropriate policies and interventions.

The data can be used for the purpose of preventive health and policy strategies that aimed to avoid and detect prenatal exposure to drugs of abuse. Additionally, there is a need to target initiatives at different social groups to help prevent drug use during pregnancy and provide support, keeping in mind that it is important to consider that substance use occurs within a complex context.

Author Contributions: Conceptualization, B.B., I.G., P.J. and A.R.; methodology and validation, B.B., I.G., E.M., R.T. and M.Á.E.; investigation, B.B., I.G., P.J., A.R., E.M., R.T. and M.Á.E.; resources, B.B. and I.G.; data curation, P.S.; writing—original draft preparation, B.B. and I.G.; writing-review and editing, B.B., I.G., P.J., A.R. and M.Á.E.; funding acquisition, B.B., I.G., P.J., A.R., E.M., R.T. and M.Á.E. All authors have read and agreed to the published version of the manuscript.

Funding: This research was funded by the Plan Nacional sobre Drogas, Ministerio de Sanidad, Servicios Sociales e Igualdad, Spain, grant number 2017I033.

Institutional Review Board Statement: The study was conducted according to the guidelines of the Declaration of Helsinki, and approved by the research ethics committee of the Balearic Islands (CEI-IB, project number IB 3538/17 IP, approved 8 January 2018).

Informed Consent Statement: Informed consent was obtained from all subjects involved in the study. 
Data Availability Statement: The data presented in this study will be made available upon request to the corresponding authors.

Acknowledgments: We thank the women of the participating neonates.

Conflicts of Interest: The authors declare no conflict of interest.

\section{References}

1. Cook, J.L.; Green, C.R.; de la Ronde, S.; Dell, C.A.; Graves, L.; Ordean, A.; Ruiter, J.; Steeves, M.; Wong, S. Epidemiology and Effects of Substance Use in Pregnancy. J. Obstet. Gynaecol. Can. 2017, 39, 906-915. [CrossRef]

2. Behnke, M.; Smith, V.C. Prenatal substance abuse: Short- and long-term effects on the exposed fetus. Pediatrics 2013, 131, e1009-e1024. [CrossRef]

3. Ross, E.J.; Graham, D.L.; Money, K.M.; Stanwood, G.D. Developmental consequences of fetal exposure to drugs: What we know and what we still must learn. Neuropsychopharmacology 2015, 40, 61-87. [CrossRef] [PubMed]

4. Luisa, M.; Navinés, R.; Gelabert, E.; Fonseca, F.; Gutierrez-zotes, A.; Guillamat, R.; Langohr, K.; Canellas, F.; Gornemann, I.; Costas, J.; et al. Substance use during pregnancy and personality dimensions [Consumo de substancias durante el embarazo y dimensiones de personalidad]. Adicciones 2020. Online ahead of print. [CrossRef]

5. Lozano, J.; García-Algar, O.; Vall, O.; De La Torre, R.; Scaravelli, G.; Pichini, S. Biological matrices for the evaluation of in utero exposure to drugs of abuse. Ther. Drug Monit. 2007, 29, 711-734. [CrossRef]

6. Hasin, D.S.; O’Brien, C.P.; Auriacombe, M.; Borges, G.; Bucholz, K.; Budney, A.; Compton, W.M.; Crowley, T.; Ling, W.; Petry, N.M.; et al. DSM-5 Criteria for Substance Use Disorders: Recommendations and Rationale. Am. J. Psychiatry 2013, 170, 834-851. [CrossRef] [PubMed]

7. Alshaarawy, O.; Anthony, J.C. Cannabis use among women of reproductive age in the United States: 2002-2017. Addict. Behav. 2019, 99, 106082. [CrossRef]

8. U.S. Department of Health and Human Services; Substance Abuse and Mental Health Services Administration Center for Behavioral Health Statistics and Quality. Results from the 2013 National Survey on Drug Use and Health: Summary of National Findings; NSDUH Series H-48; HHS Publication No. (SMA) 14-4863: Rockville, MD, USA, 2014.

9. Memo, L.; Gnoato, E.; Caminiti, S.; Pichini, S.; Tarani, L. Fetal alcohol spectrum disorders and fetal alcohol syndrome: The state of the art and new diagnostic tools. Early Hum. Dev. 2013, 89, S40-S43. [CrossRef]

10. Hoyme, H.E.; Kalberg, W.O.; Elliott, A.J.; Blankenship, J.; Buckley, D.; Marais, A.S.; Manning, M.A.; Robinson, L.K.; Adam, M.P.; Abdul-Rahman, O.; et al. Updated clinical guidelines for diagnosing fetal alcohol spectrum disorders. Pediatrics 2016, 138, e20154256. [CrossRef]

11. Cook, J.L.; Green, C.R.; Lilley, C.M.; Anderson, S.M.; Baldwin, M.E.; Chudley, A.E.; Conry, J.L.; LeBlanc, N.; Loock, C.A.; Lutke, J.; et al. Fetal alcohol spectrum disorder: A guideline for diagnosis across the lifespan. CAMJ 2016, 188, 191-197. [CrossRef] [PubMed]

12. Pichini, S.; Puig, C.; Zuccaro, P.; Marchei, E.; Pellegrini, M.; Murillo, J.; Vall, O.; Pacifici, R.; García-Algar, O. Assessment of exposure to opiates and cocaine during pregnancy in a Mediterranean city: Preliminary results of the "Meconium Project". Forensic Sci. Int. 2005, 153, 59-65. [CrossRef] [PubMed]

13. García-Algar, O.; Vall Combelles, O.; Puig Sola, C.; Mur Sierra, A.; Scaravelli, G.; Pacifici, R.; Monleón Getino, T.; Pichini, S. Exposición prenatal a drogas de abuso a través del análisis de meconio en una población de bajo nivel socioeconómico en Barcelona. An. Pediatr. (Barc.) 2009, 70, 151-158. [CrossRef] [PubMed]

14. Lendoiro, E.; González-Colmenero, E.; Concheiro-Guisán, A.; de Castro, A.; Cruz, A.; López-Rivadulla, M.; Concheiro, M. Maternal Hair Analysis for the Detection of Illicit Drugs, Medicines, and Alcohol Exposure During Pregnancy. Ther. Drug Monit. 2013, 35, 296-304. [CrossRef]

15. Garcia-Algar, O.; Kulaga, V.; Gareri, J.; Koren, G.; Vall, O.; Zuccaro, P.; Pacifici, R.; Pichini, S. Alarming Prevalence of Fetal Alcohol Exposure in a Mediterranean City. Ther. Drug Monit. 2008, 30, 249-254. [CrossRef]

16. Pichini, S.; Pellegrini, M.; Gareri, J.; Koren, G.; Garcia-Algar, O.; Vall, O.; Vagnarelli, F.; Zuccaro, P.; Marchei, E. Liquid chromatography-tandem mass spectrometry for fatty acid ethyl esters in meconium: Assessment of prenatal exposure to alcohol in two European cohorts. J. Pharm. Biomed. Anal. 2008, 48, 927-933. [CrossRef] [PubMed]

17. Consell de Mallorca. Pla Sobre Drogodependències i Altres Addiccions de Mallorca. 2015. Available online: https://www. imasmallorca.net/sites/default/files/2015-PlasobreDroguesiAltresAddiccionsdeMallorca\%28aprovat\%29_2.pdf (accessed on 31 January 2021).

18. Perlman, N.C.; Cantonwine, D.E.; Smith, N.A. Toxicology Testing in Pregnancy. Obstet. Gynecol. 2020, 136, 607-609. [CrossRef] [PubMed]

19. Ecker, J.; Abuhamad, A.; Hill, W.; Bailit, J.; Bateman, B.T.; Berghella, V.; Blake-Lamb, T.; Guille, C.; Landau, R.; Minkoff, H.; et al. Substance use disorders in pregnancy: Clinical, ethical, and research imperatives of the opioid epidemic: A report of a joint workshop of the Society for Maternal-Fetal Medicine, American College of Obstetricians and Gynecologists, and American Society of. Am. J. Obstet. Gynecol. 2019, 221, B5-B28. [CrossRef]

20. Ministerio de Sanidad, Servicios Sociales e Igualdad. Guía de Práctica Clínica de Atención en el Embarazo y Puerperio; Agencia de Evaluación de Tecnologías Sanitarias de Andalucía: Madrid, Spain, 2014. 
21. Committee Opinion No. 633. Alcohol abuse and other substance use disorders: Ethical issues in obstetric and gynecologic practice. Obs. Gynecol. 2015, 125, 1529-1537. [CrossRef]

22. Price, H.R.; Collier, A.C.; Wright, T.E. Screening Pregnant Women and Their Neonates for Illicit Drug Use: Consideration of the Integrated Technical, Medical, Ethical, Legal, and Social Issues. Front. Pharmacol. 2018, 9, 961. [CrossRef]

23. Cotten, S.W. Drug Testing in the Neonate. Clin. Lab. Med. 2012, 32, 449-466. [CrossRef]

24. Colby, J.M.; Cotton, S.W. Facing Challenges in Neonatal Drug Testing. How Laboratory Stewardship Enhances Care for a Vulnerable Population. Clinical Laboratory News AACC. 2018. Available online: https:/ /www.aacc.org/cln/articles/2018/march/ facing-challenges-in-neonatal-drug-testing (accessed on 31 January 2021).

25. Jarque, P.; Marchei, E.; Roca, A.; Gomila, I.; Pichini, S.; Busardò, F.P.; Barceló, B. The importance of biomarkers of fetal exposure to alcohol and psychotropic drugs in early diagnosis: A case report. Drug Test. Anal. 2018, 10, 895-898. [CrossRef] [PubMed]

26. ElSohly, M.A.; Stanford, D.F.; Murphy, T.P.; Lester, B.M.; Wright, L.L.; Smeriglio, V.L.; Verter, J.; Bauer, C.R.; Shankaran, S.; Bada, H.S.; et al. Immunoassay and GC-MS Procedures for the Analysis of Drugs of Abuse in Meconium. J. Anal. Toxicol. 1999, 23, 436-445. [CrossRef] [PubMed]

27. Jarque, P.; Roca, A.; Gomila, I.; Noce, V.; Barcelo, B.; Klein, J. Quantification of Methamphetamine «Shabu» in Biological Matrices to Detect Prenatal Exposure: A Case Report and a Literature Review. Curr. Pharm. Biotechnol. 2018, 19, 163-174. [CrossRef]

28. Lopez, P.; Bermejo, A.M.; Tabernero, M.J.; Cabarcos, P.; Alvarez, I.; Fernandez, P. Cocaine and Opiates Use in Pregnancy: Detection of Drugs in Neonatal Meconium and Urine. J. Anal. Toxicol. 2009, 33, 351-355. [CrossRef]

29. Tynon, M.; Porto, M.; Logan, B.K. Simplified Analysis of 11-Hydroxy-Delta-9-Tetrahydrocannabinol and 11-Carboxy-Delta-9Tetrahydrocannabinol in Human Meconium: Method Development and Validation. J. Anal. Toxicol. 2015, 39, 35-40. [CrossRef]

30. Malaca, S.; Marchei, E.; Barceló Martín, B.; Minutillo, A.; Pichini, S. Novel fast ultra-performance liquid chromatography-tandem mass spectrometry (UHPLC-MS/MS) and extraction of ethylglucuronide in meconium samples. Drug Test. Anal. 2019, 11, 1471-1475. [CrossRef]

31. Himes, S.K.; Dukes, K.A.; Tripp, T.; Petersen, J.M.; Raffo, C.; Burd, L.; Odendaal, H.; Elliott, A.J.; Hereld, D.; Signore, C.; et al. Clinical sensitivity and specificity of meconium fatty acid ethyl ester, ethyl glucuronide, and ethyl sulfate for detecting maternal drinking during pregnancy. Clin. Chem. 2015, 61, 523-532. [CrossRef]

32. Wasels, R.; Belleville, F. Gas chromatographic-mass spectrometric procedures used for the identification and determination of morphine, codeine and 6-monoacetylmorphine. J. Chromatogr. A 1994, 674, 225-234. [CrossRef]

33. Gomila, I.; Barceló, B.; Rosell, A.; Avella, S.; Sahuquillo, L.; Dastis, M. Cross-Reactivity of Pantoprazole with Three Commercial Cannabinoids Immunoassays in Urine. J. Anal. Toxicol. 2017, 41, 760-764. [CrossRef]

34. Marchei, E.; Colone, P.; Nastasi, G.G.; Calabrò, C.; Pellegrini, M.; Pacifici, R.; Zuccaro, P.; Pichini, S. On-site screening and GC-MS analysis of cocaine and heroin metabolites in body-packers urine. J. Pharm Biomed. Anal. 2008, 48, 383-387. [CrossRef]

35. Cone, E.J.; Yousefnejad, D.; Darwin, W.D.; Maguire, T. Testing Human Hair for Drugs of Abuse. II. Identification of Unique Cocaine Metabolites in Hair of Drug Abusers and Evaluation of Decontamination Procedures. J. Anal. Toxicol. 1991, 15, 250-255. [CrossRef]

36. Moore, C.; Guzaldo, F.; Donahue, T. The Determination of 11-nor-9-Tetrahydrocannabinol-9-Carboxylic Acid (THC-COOH)in Hair using Negative Ion Gas Chromatography-Mass Spectrometry and High-Volume Injection. J. Anal. Toxicol. 2001, 25, 555-558. [CrossRef]

37. Friguls, B.; Joya, X.; Garcia-Serra, J.; Gómez-Culebras, M.; Pichini, S.; Martinez, S.; Vall, O.; Garcia-Algar, O. Assessment of exposure to drugs of abuse during pregnancy by hair analysis in a Mediterranean island. Addiction 2012, 107, 1471-1479. [CrossRef]

38. Hetea, A.; Cosconel, C.; Stanescu, A.A.M.; Simionescu, A.A. Alcohol and Psychoactive Drugs in Pregnancy. Maedica (Buchar) 2019, 14, 397-401. [CrossRef]

39. European Monitoring Centre for Drugs and drug Addiction. Pregnancy, Childcare and the Family: Key Issues for Europes Response to Drugs [Internet]. 2012. Available online: http://www.emcdda.europa.eu/system/files/publications/671/TDSI120 01ENC_396469.PDF (accessed on 31 January 2021).

40. European Monitoring Centre for Drugs and Drug Addiction. Informe Sobre Drogas 2019: España. 2019. Available online: https:// www.emcdda.europa.eu/system/files/publications/11364/20191724_TDAT19001ESN_PDF.pdf (accessed on 31 January 2021).

41. Lozano, J.; García-Algar, O.; Marchei, E.; Vall, O.; Monleon, T.; Giovannandrea, R.D.; Pichin, S. Prevalence of gestational exposure to cannabis in a Mediterranean city by meconium analysis. Acta Paediatr. Int. J. Paediatr. 2007, 96, 1734-1737. [CrossRef] [PubMed]

42. García-Serra, J.; Ramis, J.; Simó, S.; Joya, X.; Pichini, S.; Vall, O.; García-Algar, O. Matrices biológicas alternativas para detectar la exposición prenatal a drogas de abuso en el tercer trimestre de la gestación. An. Pediatr. (Barc.) 2012, 77, 323-328. [CrossRef]

43. Gomez-Roig, M.D.; Marchei, E.; Sabra, S.; Busardò, F.P.; Mastrobattista, L.; Pichini, S.; Gratacós, E.; Garcia-Algar, O. Maternal hair testing to disclose self-misreporting in drinking and smoking behavior during pregnancy. Alcohol 2018, 67, 1-6. [CrossRef]

44. Concheiro, M.; Lendoiro, E.; de Castro, A.; Gónzalez-Colmenero, E.; Concheiro-Guisan, A.; Peñas-Silva, P.; Macias-Cortiña, M.; Cruz-Landeira, A.; López-Rivadulla, M. Bioanalysis for cocaine, opiates, methadone, and amphetamines exposure detection during pregnancy. Drug Test. Anal. 2017, 9, 898-904. [CrossRef] [PubMed]

45. Manich, A.; Velasco, M.; Joya, X.; García-Lara, N.R.; Pichini, S.; Vall, O.; García-Algar, O. Validity of a maternal alcohol consumption questionnaire in detecting prenatal exposure. An. Pediatr. 2012, 76, 324-328. [CrossRef] [PubMed] 
46. Joya, X.; Gomez-Culebras, M.; Callejón, A.; Friguls, B.; Puig, C.; Ortigosa, S.; Morini, L.; Garcia-Algar, O.; Vall, O. Cocaine use during pregnancy assessed by hair analysis in a Canary Islands cohort. BMC Pregnancy Childbirth 2012, 12, 2. [CrossRef] [PubMed]

47. Morini, L.; Marchei, E.; Vagnarelli, F.; Garcia Algar, O.; Groppi, A.; Mastrobattista, L.; Pichini, S. Ethyl glucuronide and ethyl sulfate in meconium and hair-potential biomarkers of intrauterine exposure to ethanol. Forensic Sci. Int. 2010, 196, 74-77. [CrossRef] [PubMed]

48. Joya, X.; Marchei, E.; Salat-Batlle, J.; García-Algar, O.; Calvaresi, V.; Pacifici, R.; Pichini, S. Fetal exposure to ethanol: Relationship between ethyl glucuronide in maternal hair during pregnancy and ethyl glucuronide in neonatal meconium. Clin. Chem. Lab. Med. 2016, 54, 427-435. [CrossRef]

49. Jackson, M.A.; Baker, A.L.; McCarter, K.L.; Brown, A.L.; Gould, G.S.; Dunlop, A.J. Interventions for pregnant women who use tobacco and other substances: A systematic review protocol. BMJ Open 2019, 9, e032449. [CrossRef]

50. Ryan, S.A.; Ammerman, S.D.; O'Connor, M.E.; Committee on Substance Use and Prevention and Section on Breastfeeding. Marijuana use during pregnancy and breastfeeding: Implications for neonatal and childhood outcomes. Pediatrics 2018, 142, e20181889. [CrossRef] [PubMed]

51. Koren, G.; Cohen, R. The use of cannabis for Hyperemesis Gravidarum (HG). J. Cannabis Res. 2020, 2, 4. [CrossRef] [PubMed]

52. Roberson, E.K.; Patrick, W.K.; Hurwitz, E.L. Marijuana use and maternal experiences of severe nausea during pregnancy in Hawai'i. Hawaii J. Med. Public Health 2014, 73, 283-287. [PubMed]

53. Ministerio de Sanidad, Servicios Sociales e Igualdad. Plan de Acción Sobre Adicciones 2018-2020. Secretaría General Técnica. Centro de Publicaciones Delegación del Gobierno para el Plan Nacional sobre Drogas. Available online: https:/ / pnsd.sanidad. gob.es/pnsd/planAccion/docs/PLAD_2018-2020_FINAL.pdf (accessed on 31 January 2021).

54. Delano, K.; Koren, G. Emerging Biomarkers of Intrauterine Neonatal and Pediatric Exposures to Xenobiotics. Pediatr. Clin. N. Am. 2012, 59, 1059-1070. [CrossRef] [PubMed]

55. Gómez Roig, M.D.; García-Algar, O. Crecimiento intrauterino restringido: ¿problema de definición o de contenido? An. Pediatr. 2011, 75, 157-160. [CrossRef] [PubMed]

56. Ostrea, E.M.; Knapp, D.K.; Tannenbaum, L.; Ostrea, A.R. Estimates of illicit drug use during pregnancy by maternal interview, hair analysis, and meconium analysis. J. Pediatr. 2001, 138, 344-348. [CrossRef] [PubMed]

57. McQueen, K.; Murphy-Oikonen, J. Neonatal abstinence syndrome. N. Engl. J. Med. 2016, 375, 2468-2479. [CrossRef] [PubMed]

58. De Santis, M.; De Luca, C.; Mappa, I.; Quattrocchi, T.; Angelo, L.; Cesari, E. Smoking, alcohol consumption and illicit drug use in an Italian population of pregnant women. Eur. J. Obstet. Gynecol. Reprod. Biol. 2011, 159, 106-110. [CrossRef]

59. Chiandetti, A.; Hernandez, G.; Mercadal-Hally, M.; Alvarez, A.; Andreu-Fernandez, V.; Navarro-Tapia, E.; Bastons-Compta, A.; Garcia-Algar, O. Prevalence of prenatal exposure to substances of abuse: Questionnaire versus biomarkers. Reprod. Health. 2017, 14, 1-12. [CrossRef] [PubMed]

60. Blasco-Alonso, M.; González-Mesa, E.; Montes, M.G.; Bravo, I.L.; Galdón, F.M.; Campos, F.C.; Marín Schiaffino, G.; Pérez Torres, S.; Herrera Peral, J.; Bellido Estévez, I. Exposición a tabaco, alcohol y drogas de abuso en gestantes. Estudio de prevalencia en gestantes de Málaga (España). Adicciones 2015, 27, 99-108. [CrossRef] [PubMed]

61. Schempf, A.H.; Strobino, D.M. Drug use and limited prenatal care: An examination of responsible barriers. Am. J. Obs. Gynecol. 2009, 200, 412.e1-412.e10. [CrossRef] [PubMed]

62. Ortigosa Gómez, S.; López-Vilchez, M.A.; Díaz Ledo, F.; Castejón Ponce, E.; Caballero Rabasco, A.; Carreras Collado, R.; Mur Sierra, A. Consumo de drogas durante la gestación y su repercusión neonatal. Análisis de los períodos 1982-1988 y 2002-2008. Med. Clin. 2011, 136, 423-430. [CrossRef]

63. Oga, E.A.; Mark, K.; Coleman-Cowger, V. Cigarette Smoking Status and Substance Use in Pregnancy. Matern. Child. Health J. 2019, 22, 1477-1483. [CrossRef]

64. Brown, R.A.; Dakkak, H.; Gilliland, J.; Seabrook, J.A. Predictors of drug use during pregnancy: The relative effects of socioeconomic, demographic, and mental health risk factors. J. Neonatal Perinat. Med. 2019, 12, 179-187. [CrossRef]

65. Grywacheski, V.; Ali, J.; Baker, M.M.; Gheorghe, M.; Wong, S.L.; Orpana, H.M. Opioid and Cannabis Use During Pregnancy and Breastfeeding in Relation to Sociodemographics and Mental Health Status: A Descriptive Study. J. Obstet. Gynaecol. Can. 2020, 43, 329-336. [CrossRef]

66. Garcia Garcia, J.; Campistol Mas, E.; López-Vilchez, M.Á.; Morcillo Buscato, M.J.; Mur Sierra, A. Análisis del maltrato prenatal en Cataluña entre los años 2011 y 2014. An. Pediatr. 2018, 88, 122-126. [CrossRef]

67. Houston-Ludlam, A.N.; Bucholz, K.K.; Grant, J.D.; Waldron, M.; Madden, P.A.F.; Heath, A.C. The interaction of sociodemographic risk factors and measures of nicotine dependence in predicting maternal smoking during pregnancy. Drug Alcohol Depend. 2019, 198, 168-175. [CrossRef]

68. Son, S.L.; Guiahi, M.; Heyborne, K.D. Historical and clinical factors associated with positive urine toxicology screening on labor and delivery. Eur J. Obstet. Gynecol. Reprod. Biol. 2018, 228, 261-266. [CrossRef] [PubMed]

69. Hans, S.L. Demographic and psychosocial characteristics of substance-abusing pregnant women. Clin. Perinatol. 1999, 26, 55-74. [CrossRef] 